\title{
Impact of taxes on purchases of close substitute foods: analysis of cross-price elasticities using data from a randomized experiment
}

Jody C. Hoenink ${ }^{1,2^{*}}$ (D) Wilma E. Waterlander ${ }^{3}$, Joreintje D. Mackenbach ${ }^{1,2}$, Cliona Ni Mhurchu ${ }^{4}$, Nick Wilson ${ }^{5}$, Joline W. J. Beulens ${ }^{1,6}$ and Nhung Nghiem ${ }^{5}$

\begin{abstract}
Objective: To examine the effects of health-related food taxes on substitution and complementary purchases within food groups, including from unhealthier to healthier alternatives and between brands.

Methods: We used data from a virtual supermarket experiment with data from 4,259 shopping events linked to varying price sets. Substitution or complementary effects within six frequently purchased food categories were analyzed. Products' own- and cross-price elasticities were analyzed using Almost Ideal Demand System models.

Results: Overall, $37.5 \%$ of cross-price elasticities were significant $(p<0.05)$ and included values greater than 0.10 . Supplementary and complementary effects were particularly found in the dairy, meats and snacks categories. For example, a $1 \%$ increase in the price of high saturated fat dairy was associated with a $0.18 \%$ (SE 0.06\%) increase in purchases of low saturated fat dairy. For name- and home-brand products, significant substitution effects were found in $50 \%(n=3)$ of cases, but only in one case this was above the 0.10 threshold.
\end{abstract}

Conclusions/policy implications: Given the relatively low own-price elasticities and the limited substitution and complementary effects, relatively high taxes are needed to substantively increase healthy food purchases at the population level.

Trial registration: This study included secondary analyses; the original trial was registered in the Australian New Zealand Clinical Trials Registry ACTRN12616000122459.

Keywords: Pricing strategies, Intervention study, Food policy, Food taxes

\section{Introduction}

A suboptimal diet is an important preventable risk factor for non-communicable diseases (NCDs) [1]. For example, high consumption of sodium and sugar

\footnotetext{
*Correspondence: j.c.hoenink@amsterdamumc.nl

${ }^{1}$ Amsterdam UMC, Vrije Universiteit Amsterdam, Department

of Epidemiology and Data Science, Amsterdam Public Health Research Institute, De Boelelaan 1089a, 1081 HV Amsterdam, the Netherlands

Full list of author information is available at the end of the article
}

sweetened beverages is associated with cardiovascular disease [2] and type 2 diabetes [3]. A systematic review investigating different intervention strategies found that health-related fiscal interventions showed the most promise in improving diets [4]. Studies investigating the effect of health-related taxes and subsidies have generally found that subsidies on healthy foods effectively increase purchases of targeted products, and taxes on unhealthy foods decrease purchases of targeted products $[4,5]$. However, these effects may not necessarily original author(s) and the source, provide a link to the Creative Commons licence, and indicate if changes were made. The images or other third party material in this article are included in the article's Creative Commons licence, unless indicated otherwise in a credit line to the material. If material is not included in the article's Creative Commons licence and your intended use is not permitted by statutory regulation or exceeds the permitted use, you will need to obtain permission directly from the copyright holder. To view a copy of this licence, visit http://creativecommons.org/licenses/by/4.0/. The Creative Commons Public Domain Dedication waiver (http://creativeco mmons.org/publicdomain/zero/1.0/) applies to the data made available in this article, unless otherwise stated in a credit line to the data. 
translate into healthier diets. For example, while studies generally find that a sugar sweetened beverages (SSB) tax decreases SSB purchases [6, 7], the effect of taxes on diet may be weakened if the taxed foods and beverages are replaced by other untaxed or cheaper unhealthy foods and beverages (hereafter referred to as foods) such as home-brand products [8].

Substitution effects are an important determinant of the ultimate impact of health-related taxes and subsidies [9]. For example, the Price ExaM Study examined the effect of subsidies and taxes on food purchasing behavior and found that a saturated fat tax resulted in a $16.2 \%(95 \% \mathrm{CI}-18.8$; -13.6$)$ decrease of saturated fat, but also a $5.0 \%(95 \%$ CI $2.1 ; 7.9)$ increase of sugar as a percentage of total energy purchased [10]. These substitution effects can be quantified using cross-price elasticity values. Positive cross-price elasticities indicate that foods are substitutes and negative cross-price elasticities indicate that foods are complements [11] and cross-price elasticities are likely to be larger when there are close substitutes/complements for a certain food (e.g., within the same food group) [12].

Currently, adequate data for the estimation of crossprice elasticities is lacking [5, 13]. When studies include cross-price elasticities, reported food groups are often highly aggregated (e.g., all soft drinks) as opposed to the level of disaggregation that is required to study detailed substitution effects (e.g., from regular soft drinks to diet soft drinks) [14]. The high level of aggregation usually arises because most studies use nutrition survey data to estimate price elasticities (i.e., modelling studies), which often do not include the level of detail needed to sufficiently estimate the price elasticities of, for example, name- and home-brand products [15]. Using empirical purchasing data provides a unique opportunity to construct the disaggregated food groups needed to be able to estimate price elasticities for smaller food groups.

Experimental studies in validated virtual supermarket environments allow for the measurement of ownand cross-price elasticities for food groups of interest before policies are implemented in real-world settings [16]. The aim of this study was to examine the substitution and complementary effects of health-related food and beverage taxes within food groups, including from unhealthier to healthier alternatives and between different brand alternatives. Our hypothesis was that if the price of products high in sugar, sodium and saturated fat would increase, individuals would substitute these products with healthier alternatives within that same food group. Also, we expected that home-brand products were substitutes for namebrand products.

\section{Methods}

We used data from the Price Experiment and Modelling (Price ExaM) Study. A study protocol for the Price ExaM Study, including a full description of the experiment and modelling methods, has been published elsewhere [17] as well as the overall results of the Price ExaM study [10, 11]. The Price ExaM Study was an experimental study conducted in 2016 in a virtual supermarket (VS) setting where participants were exposed to random price variations simulating an average New Zealand supermarket (the control price set), a fruit and vegetable subsidy, an SSB tax, a saturated fat tax, a salt tax, or a sugar tax. Full details about this study can be found elsewhere [10, 17], but a brief description is provided below.

\section{Price ExaM Study}

The main aim of the Price ExaM Study was to provide high quality evidence on the impact of health-related food taxes and subsidies by estimating precise and accurate own-price and cross-price elasticities [17]. For this, 5000 different price sets were created with random price variations for all 1411 food and beverage products within the VS [17]. In addition to including random price variations, the price sets also included systematic price variations for foods and beverages to simulate several subsidy and taxing policy scenarios, including a SSB tax (at either $20 \%$ or $40 \%)$, a saturated fat tax (NZ\$2 per $100 \mathrm{~g}$ and NZ\$4 per $100 \mathrm{~g})$, a salt tax (NZ\$0.02 per $100 \mathrm{mg}$; equivalent to NZ\$0.04 per $100 \mathrm{mg}$ sodium), a sugar tax (NZ\$0.20 per $100 \mathrm{~g}$ and NZ\$0.40 per $100 \mathrm{~g}$ ), and a 20\% fruit and vegetable subsidy. Some price sets included two or more tax and subsidy options affecting food prices.

From February 2016 to December 2016, 2352 participants were registered in the study. In total, 1132 participants were randomly assigned to the different price sets in the VS. Mean age of participants was 32.9 years (SD 12.5), $79.2 \%$ were female, $67 \%$ had completed tertiary level education, and $71.3 \%$ were New Zealand European [10]. Overall, 743 (71.6\%) completed the study (i.e., conducted all five shops). The Price ExaM Study was approved by the University of Auckland Human Participants Ethics Committee (reference 016,151) [17].

\section{Data preparation for the current study}

From the Price ExaM Study, we included data available from all 4259 shopping events; including price variations and correlating shopping patterns of 18 food categories. From this dataset, those food categories including products that were frequently purchased were selected, this included six food categories: beverages, grains, dairy, meat, sauces and snacks (including desserts). Fruit and vegetables were excluded because all products in this 
category are generally healthy and therefore the substitution effects within these groups are not of great interest from a public health perspective. All food categories were disaggregated into smaller food groups based on their sugar, sodium and saturated fat (SAFA) content. Cut-off values for low, medium or high levels of sugar/sodium/ SAFA were based on the traffic light label threshold guidelines of the United Kingdom, which can be applied to all types of foods and non-alcoholic beverages $[18,19]$. Food categories were only disaggregated into the smaller nutritional clusters when these categories included products within all three levels of sugar, sodium and/or SAFA. An example of a nutritional cluster is dairy foods with low, medium and high levels of sodium and SAFA. The food category dairy was not further disaggregated into groups of products with varying levels of sugar as no dairy products fell into the high-sugar category. Supplementary Table 1 displays the different food groups and their cut-off points and Supplementary Tables 2a and b display the food items found within the nutritional clusters.

In order to assess the overall healthiness of purchases, foods were categorized as healthy or unhealthy. This is important as it is possible for foods to contain a low amount of one adverse nutrient (e.g. sugar) but a high amount of another nutrient (e.g. sodium), meaning that such foods are not necessarily healthier overall. Fresh fish and packaged foods eligible to carry a health claim based on the New Zealand and Australian governmentendorsed nutrient profiling system (Nutrient Profiling Scoring Criterion [20]) were classified as healthy. All other foods were classified as unhealthy. Supplementary Table 3 displays the nutrient content and the percentage of products classified as healthy within the nutritional clusters. In all cases but one, low sugar/sodium/ SAFA clusters included more healthy products compared to medium or high sugar/sodium/SAFA clusters. Also, nutritional clusters high in sugar/sodium/SAFA included far less healthy products compared to nutritional clusters with medium levels of sugar/sodium/SAFA. For beverages, grains, dairy and meats, the sugar/sodium/SAFA nutrients seem to cluster together, e.g., medium and high sugar beverages also contain relatively high amounts of sodium and medium and high sodium dairy also contain high amounts of saturated fat.

For name- and home-brand food groups, food categories with at least 20 home-brand products were selected. The resulting food categories that were divided into name- and home-brand food groups included beverages, grains and snacks. The name- and home-brand food groups generally included a similar percentage of healthy products, with the exception of grains where $59.7 \%$ of name-brand products were classified as healthy compared to $80.0 \%$ of home-brand products (Supplementary Table 3).

\section{Data analyses \\ The Almost Ideal Demand System model}

Using price elasticities, we can determine the percentage change in the demand for product $\mathrm{X}$ if its own price changes (own-price elasticity) or if the price of other products (Y, Z) changes (cross-price elasticity) [21]. Typically, items that are consumed together (complementary products) have a negative cross-elasticity, while items that can be substituted (e.g., coffee for tea) have a positive cross-elasticity. In this study, substitution and complementary effects were examined using uncompensated cross-price elasticities modelled by the Almost Ideal Demand System (AIDS) [22]. Uncompensated price elasticities estimate the impact of a price increase on food purchases when consumers' money income is held constant [23]. Analysis was at the level of the household, not the individual, as participants in the virtual supermarket conducted shopping events for their entire household. Analyses were conducted using the package 'quaids' by Poi in STATA version 15.0 [24]. The package 'quaids' is a user-friendly and widely used package (e.g., [25-27]) that allows researchers to fit the AIDS model without writing their own program and to adjust for demographic variables and clustered data. Using a validated econometrics package helps with model quality control as well. Censored data are usually not a problem within the 'quaids' model when analyzing data from aggregated food groups. However, given that estimations within the package only run at a minimum of three goods within disaggregated food groups, this presented a larger problem. While data on all 4259 shopping events were used to estimate the price elasticities (i.e., no distinction between the different taxing policy scenarios were made), the data was censored as zero-purchasers were excluded from the analyses; only shopping events where participants purchased at least one product in each nutritional cluster were included (e.g., only shops with products purchased from low, medium and high nutritional clusters within the dairy category). This led to each AIDS model consisting of different numbers of shopping events. Nevertheless, the AIDS model estimated by the 'quaids' package was preferred over other models to calculate cross-price elasticities as it satisfies micro-economics restrictions such as adding-up and allowed for the estimation of uncompensated (Marshallian) elasticities. Uncompensated price elasticities are most commonly reported in studies and are arguably most relevant for policy [28].

In total, $\mathrm{N}=12$ AIDS models were run, leading to a total of $\mathrm{N}=36$ own-price elasticities and $\mathrm{N}=72$ crossprice elasticities across all food groups. Although we 
used data from a randomized experiment, our models were adjusted for age, sex, highest attained educational level, ethnicity of the main shopper and household size because the number of participants in certain arms were low [10]. Statistical significance was set at a p-value of $<0.05$ and a relevant effect size for cross-price elasticities was set at cross-price elasticities $\geq 0.10$. Results regarding the expenditure and compensated price elasticities can be found in the Supplementary Material.

\section{The double log model}

AIDS models with only two groups are reduced to only one equation to be estimated. Given the microeconomic restrictions such as adding-up and symmetry on the estimated parameters, the one equation will be reduced to a very strict functional form and hence can produce unreliable estimates [22]. Therefore, the double log model was used to calculate price elasticities for name- and homebrand products within each aggregate food category [29]. Linear mixed models with the quantity of name- or home-brand products sold within each food category were used as the dependent variable. The independent variables included the prices of the name- and homebrand products and demographic variables. In order to calculate own- and cross-price elasticities, the standard $\log$ - $\log$ functional form of the dependent and independent variables was applied, as was done in this previous study [29].

\section{Results}

Tables 1 and 2 show the data used to estimate the price elasticities for the nutritional clusters and name- and home-brand food groups (Supplementary Table 4 shows this information for the control condition and the experimental conditions separately). Fresh and frozen meats represent $24 \%$ of the total expenditure on average, while sauces only represent $6 \%$. Also, purchases of at least one item within food groups during the five-week study period varied from $8 \%$ for lowsodium sauces to $90 \%$ for low-sugar grains. The price per $100 \mathrm{~g}$ for nutritional clusters high in sugar/sodium/ SAFA within the aggregate categories grains, dairy and meat are higher compared to the nutritional clusters that are low or medium in sugar/sodium/SAFA content. Regarding name- and home-brand food groups, the price per $100 \mathrm{~g}$ of name-brand products was higher, while the purchases of name- and home-brand products was approximately equal, resulting in higher expenditures for name-brand compared to home-brand food groups (Table 2). The triangles in Fig. 1 indicate that if the price of foods increased by one percent, purchases of targeted foods decreased by approximately $0.30 \%$ to $1.10 \%$. Overall, 26 of 36 uncompensated own-price elasticities were inelastic (i.e., less than one) (Fig. 1; symbolized by triangles). In 6 out of the 12 nutritional clusters, the own-price elasticities of clusters high in sugar/sodium/SAFA were lower than the price elasticities found in low and medium sugar/ sodium/SAFA clusters.

The uncompensated cross-price elasticities show substitutive (Fig. 1; symbolized by the dots above the zero) as well as complementary (Fig. 1; symbolized by the dots below the zero) relationships with other foods within the same nutritional cluster. Larger uncertainty intervals apparent in Fig. 1 correspond to more zeropurchases within the three levels found in nutritional clusters (Table 1; column 3). Exact price elasticities displayed in Fig. 1 can be found in Supplementary Table 6 . Statistically significant substitution and complementary effects were found in $n=16(22 \%)$ and $n=26(36 \%)$ of all cases, respectively. Of these significant cross-price elasticities, $n=11$ substitutions and $n=16$ complements were larger than the cut-off of 0.10. Patterns of substitution or complementary effects differed widely between nutritional clusters, i.e., no consistent pattern of substitution or complementary purchasing was evident. Within food groups with a high level of sugar/ sodium/SAFA (i.e., food groups likely to be targeted by a health-related tax), some beneficial substitution and complementary effects were found in the food categories dairy, meats, and snacks. For example, a one percent increase in the price of high-sugar snacks was associated with $0.09 \%$ (SE 0.03) decrease in purchases of low-sugar snacks and a $0.20 \%$ (SE 0.03) increase in purchases of medium-sugar snacks (Supplementary Table 6).

For beverages and grains, own-price elasticities of name-brand products were higher than those of homebrand products (Fig. 2 and Supplementary Table 8). Statistically significant substitution effects were found in $n=3(50 \%)$ of cases, but only in one case was this above the 0.10 threshold; a one percent price increase in name-brand snacks was associated with a $0.12 \%$ (SE $0.04)$ increase in purchases of home-brand snacks.

\section{Discussion}

We investigated the effect of health-related food taxes on consumer purchases of targeted and non-targeted alternatives within the same food group in a supermarket setting. This led to the better understanding of the potential unintended product substitution and complementary effects. As also demonstrated in previous Price ExaM Studies [10, 11], taxing products high in sugar/sodium/SAFA (i.e., unhealthier foods) leads to modest decreases in purchases of targeted products according to their own-price elasticities. 
Table 1 Median price, purchases, expenditure and expenditure shares for households in the nutritional clusters (excluding zero purchases)

\begin{tabular}{|c|c|c|c|c|c|c|c|c|c|}
\hline \multirow[t]{2}{*}{$\begin{array}{l}\text { Aggregate food } \\
\text { categories }^{\mathrm{a}}\end{array}$} & \multirow[t]{2}{*}{ Nutritional clusters } & \multirow{2}{*}{$\begin{array}{l}\text { Number of shopping } \\
\text { events (\% of those } \\
\text { included compared to } \\
\text { overall shops) }\end{array}$} & \multicolumn{2}{|c|}{$\begin{array}{l}\text { Price per } \\
100 \mathrm{~g} \text { in NZ\$ }\end{array}$} & \multicolumn{2}{|c|}{$\begin{array}{l}\text { Purchased } \\
\text { quantity in } \\
\text { grams }\end{array}$} & \multicolumn{2}{|c|}{$\begin{array}{l}\text { Expenditure in } \\
\text { NZ\$ }\end{array}$} & \multirow{2}{*}{$\begin{array}{l}\text { Percentage of } \\
\text { expenditure per food } \\
\text { category out of total } \\
\text { expenditure }\end{array}$} \\
\hline & & & Median & IQR & Median & IQR & Median & IQR & \\
\hline \multirow[t]{3}{*}{ Beverages } & Low-sugar & $2386(56 \%)$ & 3.38 & 5.25 & 300 & 1400 & 7.89 & 8.29 & \multirow[t]{3}{*}{$9 \%$} \\
\hline & Medium-sugar & $3530(83 \%)$ & 0.21 & 0.07 & 3500 & 3000 & 7.02 & 7.46 & \\
\hline & High-sugar & $582(14 \%)$ & 0.52 & 0.91 & 1000 & 1135 & 3.79 & 2.21 & \\
\hline \multirow[t]{6}{*}{ Grains } & Low-sugar & 3815 (90\%) & 0.52 & 0.33 & 1982 & 2300 & 10.52 & 11.22 & \multirow[t]{6}{*}{$11 \%$} \\
\hline & Medium-sugar & $1361(32 \%)$ & 1.11 & 0.73 & 500 & 440 & 5.50 & 3.97 & \\
\hline & High-sugar & $932(22 \%)$ & 1.14 & 1.28 & 650 & 1000 & 6.00 & 4.49 & \\
\hline & Low-sodium & $2540(60 \%)$ & 0.32 & 0.29 & 1500 & 1650 & 5.38 & 5.82 & \\
\hline & Medium-sodium & $3696(87 \%)$ & 0.68 & 0.41 & 1360 & 1470 & 9.23 & 10.48 & \\
\hline & High-sodium & $906(21 \%)$ & 1.49 & 1.23 & 350 & 530 & 4.46 & 1.84 & \\
\hline \multirow[t]{6}{*}{ Dairy } & Low-sodium & 3599 (85\%) & 0.27 & 0.14 & 3000 & 2375 & 8.75 & 8.62 & \multirow[t]{6}{*}{$12 \%$} \\
\hline & Medium-sodium & $474(11 \%)$ & 2.54 & 2.11 & 250 & 300 & 6.52 & 4.61 & \\
\hline & High-sodium & 2181 (51\%) & 1.85 & 1.59 & 900 & 750 & 11.15 & 7.24 & \\
\hline & Low-SAFA & $1271(30 \%)$ & 0.25 & 0.44 & 2000 & 1250 & 5.38 & 3.82 & \\
\hline & Medium-SAFA & 3114 (73\%) & 0.25 & 0.14 & 2225 & 2000 & 7.04 & 6.65 & \\
\hline & High-SAFA & 2455 (58\%) & 1.81 & 1.47 & 900 & 650 & 11.75 & 9.15 & \\
\hline \multirow[t]{6}{*}{ Meat } & Low-SAFA & 3065 (72\%) & 1.91 & 0.71 & 750 & 760 & 13.14 & 14.38 & \multirow[t]{6}{*}{$24 \%$} \\
\hline & Medium-SAFA & 3155 (74\%) & 1.93 & 0.62 & 855 & 900 & 16.31 & 17.28 & \\
\hline & High-SAFA & $2512(59 \%)$ & 1.79 & 0.78 & 770 & 770 & 12.63 & 12.40 & \\
\hline & Low-sodium & 3491 (82\%) & 1.95 & 0.61 & 1210 & 1250 & 23.51 & 25.56 & \\
\hline & Medium-sodium & 2617 (61\%) & 1.72 & 0.62 & 600 & 610 & 9.90 & 10.64 & \\
\hline & High-sodium & $1522(36 \%)$ & 1.97 & 1.14 & 480 & 500 & 10.31 & 9.04 & \\
\hline \multirow{6}{*}{$\begin{array}{l}\text { Sauces and season- } \\
\text { ings }\end{array}$} & Low-sugar & $1614(38 \%)$ & 1.18 & 1.35 & 495 & 470 & 4.89 & 4.27 & \multirow[t]{6}{*}{$6 \%$} \\
\hline & Medium-sugar & 1212 (29\%) & 1.19 & 0.97 & 400 & 300 & 4.29 & 2.71 & \\
\hline & High-sugar & $1206(28 \%)$ & 1.10 & 0.60 & 520 & 460 & 5.04 & 4.28 & \\
\hline & Low-sodium & 357 (8\%) & 1.25 & 0.74 & 500 & 30 & 6.63 & 3.17 & \\
\hline & Medium-sodium & 1679 (39\%) & 0.90 & 0.62 & 500 & 581 & 4.87 & 4.53 & \\
\hline & High-sodium & 1664 (39\%) & 1.44 & 0.88 & 400 & 380 & 5.18 & 4.83 & \\
\hline \multirow[t]{9}{*}{ Snacks } & Low-sugar & 2589 (61\%) & 1.64 & 0.83 & 350 & 390 & 5.47 & 6.21 & \multirow[t]{9}{*}{$11 \%$} \\
\hline & Medium-sugar & 1840 (43\%) & 1.33 & 1.26 & 420 & 750 & 5.52 & 4.90 & \\
\hline & High-sugar & $2828(66 \%)$ & 1.77 & 0.84 & 490 & 690 & 8.40 & 9.42 & \\
\hline & Low-sodium & 2675 (63\%) & 1.74 & 1.43 & 500 & 1062 & 7.93 & 9.02 & \\
\hline & Medium-sodium & $2723(64 \%)$ & 1.57 & 0.66 & 450 & 540 & 6.99 & 7.92 & \\
\hline & High-sodium & 1871 (44\%) & 1.66 & 0.75 & 250 & 270 & 4.19 & 4.32 & \\
\hline & Low-SAFA & 2011 (47\%) & 1.43 & 1.04 & 375 & 375 & 4.51 & 4.65 & \\
\hline & Medium-SAFA & 1729 (41\%) & 1.87 & 0.98 & 250 & 290 & 4.78 & 4.84 & \\
\hline & High-SAFA & $3163(74 \%)$ & 1.66 & 0.86 & 600 & 925 & 9.81 & 11.67 & \\
\hline
\end{tabular}

${ }^{a}$ Milk is considered a beverage as well as a dairy product - all other foods and beverages are mutually exclusive within the nutritional clusters Abbreviations: IQR Interquartile Range

Uncompensated price elasticities showed both complementary and substitution effects within some specific unhealthier food clusters. Furthermore, substitutions from name-brand to home-brand beverages and snacks were observed, but these were relatively small (i.e., most were smaller than 0.10).
We found that if the prices of foods increased by $10 \%$, purchases of targeted foods typically decreased by approximately $3 \%$ to $11 \%$. Most uncompensated own-price elasticities were inelastic (i.e., smaller than 1 in absolute value). This finding is in line with previous studies $[9,30]$ and unsurprising given the fact that 
Table 2 Median price, purchases, expenditure and expenditure shares for households in name- and home-brand food groups (excluding zero purchases)

\begin{tabular}{|c|c|c|c|c|c|c|c|c|}
\hline \multirow[t]{2}{*}{$\begin{array}{l}\text { Aggregate food } \\
\text { categories }\end{array}$} & \multirow[t]{2}{*}{$\begin{array}{l}\text { Name- and home- } \\
\text { brand food groups }\end{array}$} & \multirow{2}{*}{$\begin{array}{l}\text { Number of shops (\% of shops } \\
\text { included compared to overall } \\
\text { shops) }\end{array}$} & \multicolumn{2}{|c|}{$\begin{array}{l}\text { Price per } 100 \mathrm{~g} \text { in } \\
\text { NZ\$ }\end{array}$} & \multicolumn{2}{|c|}{$\begin{array}{l}\text { Purchased quantity } \\
\text { in grams }\end{array}$} & \multicolumn{2}{|c|}{$\begin{array}{l}\text { Expenditure in } \\
\text { NZ\$ }\end{array}$} \\
\hline & & & Median & IQR & Median & IQR & Median & IQR \\
\hline \multirow[t]{2}{*}{ Beverages } & Name-brand & 3189 (75\%) & 0.43 & 0.91 & 2000 & 3226 & 10.13 & 12.04 \\
\hline & Home-brand & 2447 (58\%) & 0.19 & 0.06 & 2000 & 2000 & 4.89 & 4.69 \\
\hline \multirow[t]{2}{*}{ Grains } & Name-brand & 3474 (82\%) & 0.81 & 0.48 & 1400 & 1555 & 10.74 & 11.98 \\
\hline & Home-brand & 2619 (62\%) & 0.30 & 0.16 & 1500 & 1890 & 4.71 & 5.73 \\
\hline \multirow[t]{2}{*}{ Snacks } & Name-brand & 3390 (80\%) & 1.76 & 0.72 & 647 & 870 & 10.99 & 13.46 \\
\hline & Home-brand & $2021(48 \%)$ & 1.16 & 0.96 & 390 & 700 & 5.17 & 5.05 \\
\hline
\end{tabular}

Abbreviations: IQR Interquartile Range

food is considered a necessity. In approximately half of the clusters, the own-price elasticities of clusters high in sugar/sodium/SAFA were lower compared to clusters with low and medium amounts of sugar/sodium/SAFA. The largely inelastic own-price elasticities and the even lower own-price elasticities of clusters high in sugar/ sodium/SAFA compared to clusters with lower amounts of sugar/sodium/SAFA suggests that when implementing taxes to achieve health goals, it may be preferable to apply substantive taxes (i.e., above $20 \%$ [31, 32]). Although the percentage decrease in purchases is disproportionate to the percentage increase in price, larger taxes will lead to larger purchasing changes compared to smaller taxes.

We observed that health-related taxes alter food and beverage purchases in a rather complex fashion, with only some of the substitution and complementary effects supporting the goal of the health-related taxes. Patterns in uncompensated cross-price elasticities varied between food categories, where some substitution or complementary effects towards healthier options were observed in snacks, meat and dairy and no effects were observed in beverages, grains and sauces. When it came to substitutions from name-brand foods to home-brand foods, we found that within two of the three food categories examined (i.e., beverages and snacks), cheaper and equally unhealthy home-brand foods were substituted for namebrand foods.

Given the detailed data needed to estimate these cross-price elasticities, few similar studies are available with which to compare our results. The finding that name- and home-brand products are substitutes has been reported previously, but including smaller food groups (e.g., breakfast cereals and mayonnaise) [14]. Regarding within food group substitutions to healthier alternatives, most studies to date have focused on beverages. Our findings suggest that if the price of sugary beverages increases, individuals purchase fewer taxed sugary beverages, but there is no change in the purchases of healthier beverages. However, previous evidence suggests that a SSB tax leads to substitutions with water (albeit not at a statistically significant level) [6, 33, 34]. Furthermore, similar to this study, a paper investigating cross-price elasticities within nutritionally clustered food groups using supermarket food purchasing data found relatively small within food group substitution effects [30].

The results of the uncompensated price elasticities analyses seem to imply that within food group substitutions and complements contributed minimally to the effects found in the main Price ExaM Study where a saturated fat, sugar and salt tax led to a $16 \%, 5 \%$ and $20 \%$ decrease in purchases of saturated fat, sugar and sodium as a percentage of total energy [10]. While the current study found limited substitution or complementary purchases, it is possible that between food group substitutions have taken place [30]. A study that investigated between food groups substitutions found for example that a $10 \%$ price increase in high-sugar soft drinks led to a $1 \%$ increase in the purchases of chocolate and confectionary [21]. Based on the small health-related substitution and complementary effects found in this study, it seems that the indirect effects of health-related food taxes do not necessarily enhance the overall health effects. However, these strategies also do not seem to lead to any unintended effects either.

While there is a wealth of evidence demonstrating that health-related taxes lead to healthier food purchases $[4,5,9]$, it is still important to further investigate potential unintended effects of health-related taxes on food purchases and consumption. It is likely that not many studies have attempted to calculate cross-price elasticities within food groups due to the detailed and large dataset required. While we attempted to describe 
$1 \%$ price increase of low, medium or high SAFA containing categories

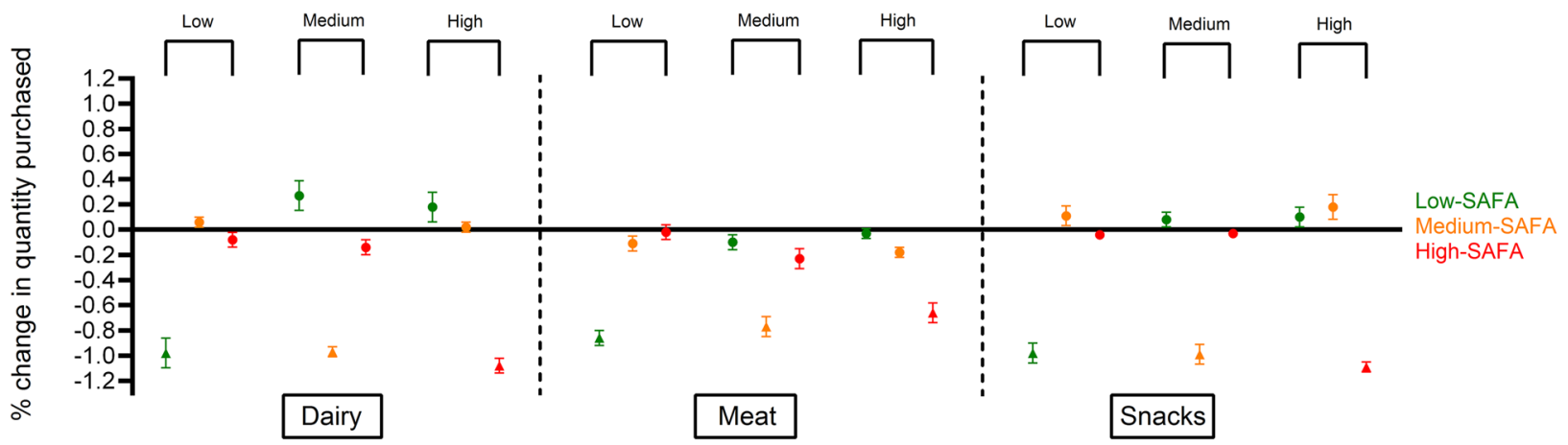

$1 \%$ price increase of low, medium or high sugar containing categories

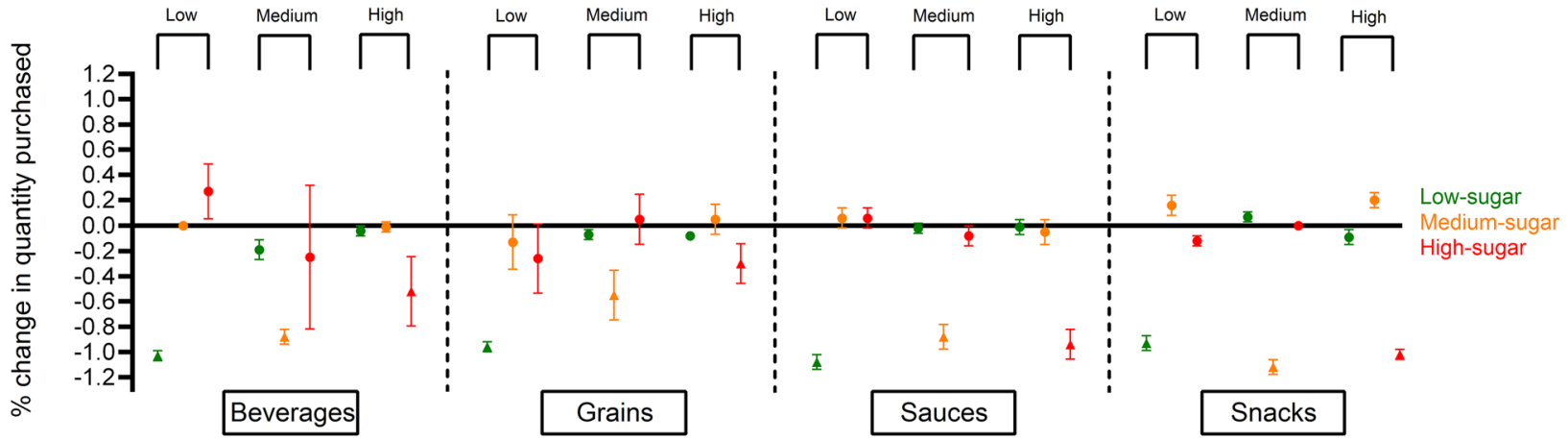

$1 \%$ price increase of low, medium or high sodium containing categories

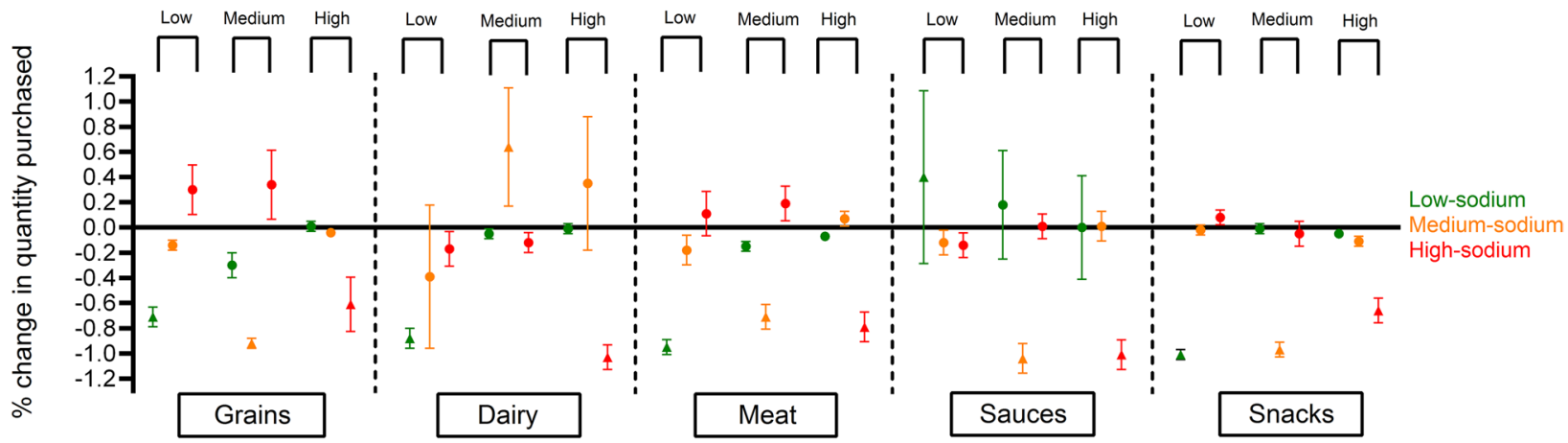

Fig. 1 Change in demand (\%) as a response to a 1\% price increase of low, medium or high SAFA/sugar/salt containing categories adjusted for demographic variables. Uncompensated own-price elasticities are displayed as triangles and uncompensated cross-price elasticities are displayed as dots. Dots above the line represent substitution effects and dots below the line represent complementary effects

the unintended effects of health-related taxes on food purchases of close substitutes, our estimations may suffer from selection bias as the dataset is censored because zero-purchasers were excluded. This bias may differ by food groups; the percentage of shopping events included in the sauces and seasoning category ranged from 8 to $39 \%$ of the total observations, while this percentage in the meat category ranged from 36 to $82 \%$. A previous study compared a quadratic AIDS model adjusted for zero purchases to a quadratic AIDS 


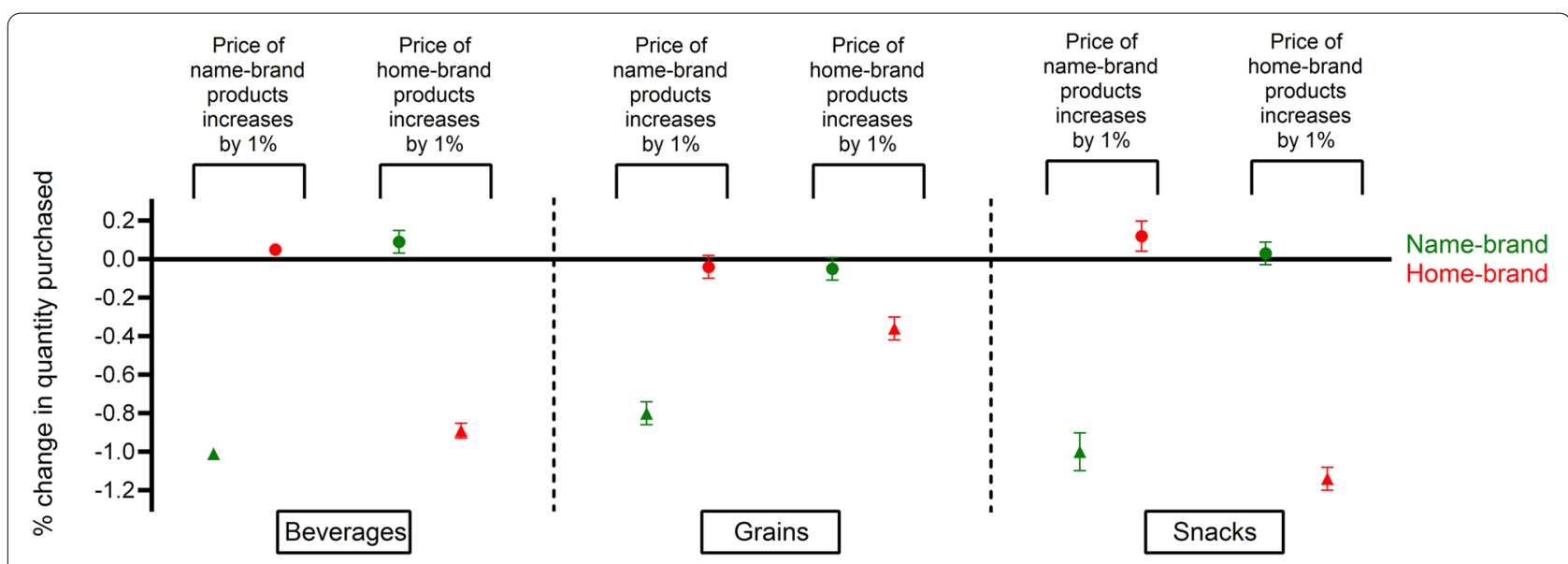

Fig. 2 Change in demand (\%) as a response to a 1\% price increase in name- and home-brand categories adjusted for demographic variables. Own-price elasticities are displayed as triangles and cross-price elasticities are displayed as dots. Dots above the line represent substitution effects and dots below the line represent complementary effects

model unadjusted for zero purchases, and found that the price elasticities in the unadjusted model were smaller than those found in the adjusted model [12]. The results from this previous study suggest that our results provide a conservative estimate. Nevertheless, the AIDS model was preferred over more simple models that account for zero purchases (e.g., double hurdle models) as it satisfies micro-economics restrictions such as adding-up. Also, this study makes an implicit assumption that substitutions only take place within food groups; between food group substitutions could also take place. This may contradict the basis of AIDS models imposing prior constraints on the substitution process. Nevertheless, our approach implicitly assumed a multistage demand model [35] and this multistage demand model has been previously used in combination with an AIDS model [36]. More research regarding substitution effects of name- and home-brand products within other food categories is needed. Also, the effects of price changes on substitutions from unhealthy to healthier products within other categories (e.g., readymade meals) could be investigated, but would require an even larger sample size than the present. Furthermore, as responses to price changes likely vary by cultural norms, more culture-specific and context-specific research is needed [10].

By gaining more insight into substitution and complementary effects, health-related taxes can be adapted correspondingly to further increase its effectiveness on food purchases. One example of investigating the impact of unintended cross price elasticities is to model food pricing interventions through a multistate lifetable in order to calculate health outcomes for a specific population [11]. However, it should be noted that as our uncompensated cross-price elasticities were estimated based on the assumption that food expenditure was held constant, some adjustment must be made (e.g., using the total food expenditure elasticity) when using the price elasticities to calculate food purchases [37].

Strengths of this study included the randomized repeated measures design allowing us to collect precise and specific food price elasticity data [10] and the relatively large sample size. This allowed for the construction of nutritional clusters that represent distinct sets of products within various food categories, which is often not possible when using subjective measures and lessdetailed data. A limitation of this study-not including the limitations with regards to the AIDS model described above-is that despite that the VS environment has been validated and reflects real life purchases, virtual purchases may not be directly generalizable to the real world. For example, price changes in the virtual environment were not conveyed to participants, whereas real-life price changes are often communicated to consumers, likely resulting in larger effects [38].

\section{Conclusion}

This study examined the impact of health-related food taxes on purchasing of close substitute foods. Analyses presented suggest that food taxes lead to minimal within food group substitutions or complements. Given the relatively low own-price elasticities and the limited healthrelated substitution and complementary effects, relatively high tax rates are needed to substantively increase the proportion of healthy food purchases at the population level. 


\section{Supplementary Information}

The online version contains supplementary material available at https://doi. org/10.1186/s12937-021-00736-y.

Additional file 1: Supplementary Table 1. Food category and corresponding food classification to food groups based on sugar, sodium or SAFA content of products. Supplementary File 2a. List of smaller food groups found within the aggregate food categories. Supplementary File $\mathbf{2} \mathbf{b}$. List of smaller food groups found within the aggregate homebrand and name-brand categories. Supplementary Table 3. Median nutritional content per serving and percentage of healthy foods within the aggregated categories. Supplementary Table 4a. Percentage change in price, expenditure and quantity between the control condition and the experimental conditions for nutrient-based food groups. Supplementary Table 5. Mean expenditure elasticities and standard errors for all nutrientbased food groups. Supplementary Table 6 . Uncompensated elasticities and corresponding standard errors (shaded boxes showing own price elasticities, others being cross price elasticities). Supplementary Table 7. Compensated elasticities and corresponding standard errors (shaded boxes showing own price elasticities, others being cross price elasticities). Supplementary Table 8. Price elasticities and standard errors from the double log model for name- and home-brand products within the food categories.

\section{Acknowledgements}

We would like to acknowledge the Price ExaM Study team. We would also like to acknowledge Tony Blakely for his input on the methods section in this study.

\section{Authors' contributions}

Wilma E. Waterlander, Nick Wilson and Cliona Ni Mhurchu conceived and designed the project. Wilma E. Waterlander designed the experiment. Wilma E. Waterlander and Cliona Ni Mhurchu designed the virtual supermarket software. Wilma E. Waterlander led the data collection and analysis. Jody C. Hoenink, Wilma E. Waterlander, Joreintje D. Mackenbach, Joline W.J. Beulens and Nhung Nghiem constructed the analysis plan. Jody C. Hoenink and Nhung Nghiem analysed the data and interpreted the results. Jody C. Hoenink drafted the manuscript and all authors revised the manuscript critically for important intellectual content. All authors read, provided input to, and approved the final version of the manuscript.

\section{Funding}

The Price ExaM Study was funded by a programme grant from the Health Research Council of New Zealand (13/724). JCH received a travel grant from the Methodology research group of the research institute Amsterdam Public Health. JDM is funded by an NWO VENI grant on "Making the healthy choice easier - role of the local food environment" (grant number 451-17-032). The Supreme Nudge (CVON2016-04) project, and the work of JCH and JDM, is funded by the Netherlands Heart Foundation and the Netherlands Organization for Health Research and Development (ZonMw).

\section{Availability of data and materials}

Requests for de-identified individual participant data or study documents will be considered where the proposed use aligns with public positive purposes, does not conflict with other requests or planned use by the trial steering committee, and the requestor is willing to sign a data access agreement. Contact is through NN. The protocol for the Price ExaM Study is available from WEW on request, and the protocol for the current study is available from $\mathrm{JCH}$ on request.

\section{Declarations}

Ethics approval and consent to participate

The study complies with the Declaration of Helsinki. The Price ExaM Study was approved by the University of Auckland Human Participants Ethics Committee (reference 016151).

\section{Consent for publication}

Not applicable.

\section{Competing interests}

The authors have declared that no competing interests exist.

\section{Author details}

${ }^{1}$ Amsterdam UMC, Vrije Universiteit Amsterdam, Department of Epidemiology and Data Science, Amsterdam Public Health Research Institute, De Boelelaan 1089a, 1081 HV Amsterdam, the Netherlands. ${ }^{2}$ Upstream Team, www.upstreamteam.nl, Amsterdam UMC, Amsterdam, The Netherlands. ${ }^{3}$ Amsterdam UMC, Department of Public and Occupational Health, University of Amsterdam, Amsterdam Public Health Research Institute, Meibergdreef 9. Amsterdam, the Netherlands. ${ }^{4}$ National Institute for Health Innovation, University of Auckland, Auckland, New Zealand. ${ }^{5}$ Department of Public Health, University of Otago, Wellington, New Zealand. ${ }^{6}$ Julius Center for Health Sciences and Primary Care, University Medical Center Utrecht, Utrecht University, Utrecht, the Netherlands.

Received: 20 January 2021 Accepted: 30 August 2021

Published online: 07 September 2021

\section{References}

1. Afshin A, Sur PJ, Fay KA, Cornaby L, Ferrara G, Salama JS, et al. Health effects of dietary risks in 195 countries, 1990-2017: a systematic analysis for the Global Burden of Disease Study 2017. The Lancet. 2019;393(10184):1958-72.

2. Strazzullo P, D'Elia L, Kandala N-B, Cappuccio FP. Salt intake, stroke, and cardiovascular disease: meta-analysis of prospective studies. BMJ. 2009:339:b4567.

3. Imamura F, O'Connor L, Ye Z, Mursu J, Hayashino Y, Bhupathiraju SN, et al. Consumption of sugar sweetened beverages, artificially sweetened beverages, and fruit juice and incidence of type 2 diabetes: systematic review, meta-analysis, and estimation of population attributable fraction. BMJ. 2015;351:h3576.

4. Hartmann-Boyce J, Bianchi F, Piernas C, Riches SP, Frie K, Nourse R, et al. Grocery store interventions to change food purchasing behaviors: a systematic review of randomized controlled trials. Am J Clin Nutr. 2018;107(6):1004-16.

5. Afshin A, Penalvo JL, Del Gobbo L, Silva J, Michaelson M, O'Flaherty $M$, et al. The prospective impact of food pricing on improving dietary consumption: a systematic review and meta-analysis. PLOS ONE. 2017:12(3):e0172277.

6. Silver LD, Ng SW, Ryan-Ibarra S, Taillie LS, Induni M, Miles DR, et al. Changes in prices, sales, consumer spending, and beverage consumption one year after a tax on sugar-sweetened beverages in Berkeley, California, US: A before-and-after study. PLoS Med. 2017;14(4):e1002283.

7. Colchero MA, Molina M, Guerrero-Lopez CM. After Mexico implemented a tax, purchases of sugar-sweetened beverages decreased and water increased: difference by place of residence, household composition, and income level. J Nutr. 2017;147(8):1552-7.

8. Fletcher J. Soda taxes and substitution effects: will obesity be affected? Choices. 2011;26(3):1-4.

9. Andreyeva T, Long MW, Brownell KD. The impact of food prices on consumption: a systematic review of research on the price elasticity of demand for food. Am J Public Health. 2010;100(2):216-22.

10. Waterlander WE, Jiang Y, Nghiem N, Eyles H, Wilson N, Cleghorn C, et al. The effect of food price changes on consumer purchases: a randomised experiment. Lancet Public Health. 2019;4(8):e394-405.

11. Blakely T, Cleghorn C, Mizdrak A, Waterlander W, Nghiem N, Swinburn B, et al. The effect of food taxes and subsidies on population health and health costs: a modelling study. The Lancet Public Health. 2020;5(7):e404-13.

12. Bronnmann J, Guettler S, Loy J-P. Efficiency of correction for sample selection in QUAIDS models: an example for the fish demand in Germany. Empirical Econ. 2019;57(4):1469-93.

13. Mizdrak A, Scarborough P, Waterlander WE, Rayner M. Differential responses to food price changes by personal characteristic: a systematic review of experimental studies. PLoS ONE. 2015;10(7):e0130320.

14. Akbay C, Jones E. Food consumption behavior of socioeconomic groups for private labels and national brands. Food Qual Prefer. 2005;16(7):621-31. 
15. Thow AM, Downs S, Jan S. A systematic review of the effectiveness of food taxes and subsidies to improve diets: understanding the recent evidence. Nutr Rev. 2014;72(9):551-65.

16. Waterlander WE, Jiang Y, Steenhuis IH, Ni Mhurchu C. Using a 3D virtual supermarket to measure food purchase behavior: a validation study. J Med Internet Res. 2015;17(4):e107.

17. Waterlander WE, Blakely T, Nghiem N, Cleghorn CL, Eyles H, Genc M, et al. Study protocol: combining experimental methods, econometrics and simulation modelling to determine price elasticities for studying food taxes and subsidies (The Price ExaM Study). BMC Public Health. 2016:16:601.

18. Federal Register of Legislation [Internet]. Australia New Zealand Food Standards Code - Schedule 4 - Nutrition, health and related claims [updated 2017; cited 2019 June 12]. Available from https://www.legis lation.gov.au/Details/F2017C00711.

19. Department of Health [Internet]. Guide to creating a front of pack (FoP) nutrition label for pre-packed products sold through retail outlets [updated 2016; cited 2019 June 12]. Available from https:// www.food.gov.uk/sites/default/files/media/document/fop-guida nce_0.pdf

20. Food Standards Australia New Zealand [Internet]. Short guide for industry to the Nutrient Profiling Scoring Criterion in Standard 1.2.7 [updated 2016; cited 2019 June 12]. Available from http://www.foods tandards.gov.au/industry/labelling/Documents/Short-guidefor-indus try-to-the-NPSC.pdf.

21. Smith RD, Cornelsen L, Quirmbach D, Jebb SA, Marteau TM. Are sweet snacks more sensitive to price increases than sugar-sweetened beverages: analysis of British food purchase data. BMJ Open. 2018;8(4):e019788.

22. Deaton A, Muellbauer J. An almost ideal demand system. Am Econ Rev. 1980;70(3):312-26.

23. Clements KW, Si J. Price elasticities of food demand: compensated vs uncompensated. Health Econ. 2016;25(11):1403-8.

24. Poi BP. Easy demand-system estimation with quaids. Stand Genomic Sci. 2012;12(3):433-46.

25. Guerrero-López CM, Unar-Munguía M, Colchero MA. Price elasticity of the demand for soft drinks, other sugar-sweetened beverages and energy dense food in Chile. BMC Public Health. 2017;17(1):1-8.

26. Hoang HK. Analysis of food demand in Vietnam and short-term impacts of market shocks on quantity and calorie consumption. Agric Econ. 2018;49(1):83-95.

27. Khanal AR, Mishra AK, Keithly W. Heterogeneity in food demand among rural Indian households: The role of demographics. Can J Agric Econ/ Revue canadienne d'agroeconomie. 2016:64(3):517-44.
28. Cornelsen L, Green R, Turner R, Dangour AD, Shankar B, Mazzocchi M, et al. What happens to patterns of food consumption when food prices change? Evidence from a systematic review and meta-analysis of food price elasticities globally. Health Econ. 2015;24(12):1548-59.

29. Meng Y, Brennan A, Purshouse R, Hill-McManus D, Angus C, Holmes J, et al. Estimation of own and cross price elasticities of alcohol demand in the UK-A pseudo-panel approach using the Living Costs and Food Survey 2001-2009. J Health Econ. 2014;34:96-103.

30. Harding $M$, Lovenheim $M$. The effect of prices on nutrition: comparing the impact of product- and nutrient-specific taxes. J Health Econ. 2017:53:53-71.

31. Mytton OT, Clarke D, Rayner M. Taxing unhealthy food and drinks to improve health. BMJ. 2012;344:e2931.

32. Niebylski ML, Redburn KA, Duhaney T, Campbell NR. Healthy food subsidies and unhealthy food taxation: A systematic review of the evidence. Nutrition. 2015;31(6):787-95.

33. Colchero MA, Popkin BM, Rivera JA, Ng SW. Beverage purchases from stores in Mexico under the excise tax on sugar sweetened beverages: observational study. BMJ. 2016;352:h6704.

34. Teng AM, Jones AC, Mizdrak A, Signal L, Genc M, Wilson N. Impact of sugar-sweetened beverage taxes on purchases and dietary intake: Systematic review and meta-analysis. Obes Rev. 2019;20(9):1187-204.

35. Edgerton DL. Weak separability and the estimation of elasticities in multistage demand systems. Am J Agr Econ. 1997;79(1):62-79.

36. Briggs AD, Mytton OT, Kehlbacher A, Tiffin R, Rayner M, Scarborough P. Overall and income specific effect on prevalence of overweight and obesity of 20\% sugar sweetened drink tax in UK: econometric and comparative risk assessment modelling study. BMJ. 2013;347:f6189.

37. Blakely T, Nghiem N, Genc M, Mizdrak A, Cobiac L, Mhurchu CN, et al. Modelling the health impact of food taxes and subsidies with price elasticities: The case for additional scaling of food consumption using the total food expenditure elasticity. PLoS ONE. 2020;15(3):e0230506.

38. Hoenink JC, Mackenbach JD, Waterlander W, Lakerveld J, van der Laan N, Beulens JW. The effects of nudging and pricing on healthy food purchasing behavior in a virtual supermarket setting: a randomized experiment. IJBNPA. 2020;17(1):1-12.

\section{Publisher's Note}

Springer Nature remains neutral with regard to jurisdictional claims in published maps and institutional affiliations.
Ready to submit your research? Choose BMC and benefit from:

- fast, convenient online submission

- thorough peer review by experienced researchers in your field

- rapid publication on acceptance

- support for research data, including large and complex data types

- gold Open Access which fosters wider collaboration and increased citations

- maximum visibility for your research: over $100 \mathrm{M}$ website views per year

At BMC, research is always in progress.

Learn more biomedcentral.com/submissions 